\title{
An in-vitro analysis of shear bond strength of resin based luting cements to lithium disilicate glass ceramic
}

\author{
K.Premnath $^{1^{*}}$, Nagaranjani Prakash ${ }^{2}$, Mohammed Ajmal B ${ }^{3}$, Syed Ahmed Raheel ${ }^{4}$ \\ ${ }^{\mathbf{1}}$ Professor, ${ }^{\mathbf{2}}$ Assistant Professor, ${ }^{\mathbf{3}}$ Senior Lecturer, ${ }^{\mathbf{4}}$ Reader, ${ }^{\mathbf{1 - 4}}$ Dept. of Prosthodontics, ${ }^{\mathbf{1 , 3}, \mathbf{4}} \mathrm{KGF}$ College of Dental Sciences and Hospital, \\ Kolar, Karnataka, India
}

*Corresponding Author: K.Premnath

Email: rahil1484@gmail.com

\begin{abstract}
Lithium-disilicate glass-ceramic (LDGC) material was introduced in the year 2000; it improved the strength of single and multiple-unit restorations. The inherent brittleness and limited flexural strength of the available glass-ceramic material were the major drawbacks of these restorations. Adequate adhesion between ceramic and tooth substructure was vital for the successful functioning of ceramic restoration. Limited information is available about the currently available luting systems.

Aims and objectives: The present in-vitro study was designed to compare and evaluate the shear bond strength of three different resin based luting cements to lithium disilicate glass ceramic. The study was conducted to evaluate the shear bond strength of different resin based luting cements to lithium disilicate glass ceramic.

Methods and Methodology: Thirty lithium disilicate glass ceramic disks were fabricated and were surface treated. The ceramic specimen were divided into three groups that received three different luting cements (Group 1: RelyX Ultimate Clicker, Group 2: Fusion Self Lute and Group 3: ParaCore). The shear bond strength of adhesive resin cement to the ceramic substrate was then measured with a Universal testing machine (Multitest 10-I, Mecmesin). Following de-bonding, all fractured interfaces were visually analysed from the Scanning electron microscope photomicrographs to determine the mode of fracture.

Results: The study results demonstrated that there was no statistical significant difference between RelyX and Fusion Self Lute while there was statistically significant difference between RelyX and ParaCore $(\mathrm{p}=0.019, \mathrm{p}<0.05)$ and Fusion Self Lute and ParaCore ( $\mathrm{p}=0.03$, $\mathrm{p}<0.05)$.

Conclusion: the study concluded that the resin cements containing filler particles show higher bond strength values when compared to resin cements with no filler particles and bonds which fail by cohesion exhibit high-strength performance.
\end{abstract}

Keywords: luting, Ceramic, High- strength.

\section{Introduction}

Established alternative solutions and transforming traditional methods can be challenging to dental restorative teams due to increasing patient demands. Many efforts have been made to develop ceramic systems to remove metal infrastructures and provide optimal distribution of reflected light. A wide range of all ceramic restorations are available which provide high quality aesthetics.

Leucite-reinforced glass ceramics (LRGC), developed in early 1990s had leucite crystals in an amorphous glass matrix. The leucite particles strengthen the ceramic restorations however they have the limitation to crack propagation. The ability to acid etch the surface and bond to the tooth structure greatly improved the predictability and survival of these restorations. ${ }^{1}$ LRGC restorations have revolutionized modern-day esthetic dentistry.

Adhesion between cement and ceramic surfaces requires surface pretreatment to improve the retention, marginal adaptation and fracture resistance of the restorations.

Studies have shown that inappropriate cementation techniques lead to clinical failure. The internal surface of the ceramic restoration must be prepared so as to optimize micromechanical retention of the cement into the ceramic substructure. Surface treatment of porcelain increases the surface area and creates micro-porosities on the surface, thereby increasing the potential for mechanical retention of the cement. ${ }^{2}$
Different surface treatment methods such as grinding, abrasion with diamond rotary instruments, airborne particle abrasion with $\mathrm{Al} 2 \mathrm{O} 3$, acid etching, sandblasting and combinations of any of these methods have been suggested to provide roughness and increase micromechanical retention. ${ }^{3}$

Acid etching using hydrofluoric (HF) acid can achieve proper surface texture and roughness. ${ }^{4,5}$ The glassy matrix is selectively removed, and crystalline structures are exposed. Extensive evaluation of Empress 2 material has been conducted in both laboratory and clinical studies, however, limited information is available concerning the adhesive characteristics of currently available luting systems. ${ }^{6-14}$ Furthermore, due to the new chemical composition of the material, information about the surface preparations applicable to the lithium disilicate based material was insufficient.

The present study was conducted to get an understanding on how the commonly available luting systems namely RelyX, Fusion Self Lute and ParaCore bond with all ceramic restorations.

\section{Aim and Objectives}

An in vitro study was performed to compare and evaluate the shear bond strength of three different resin based luting cements to lithium disilicate glass ceramic. The study objective was to evaluate the shear bond strength of different resin based luting cements to lithium disilicate 
glass ceramic, to compare the shear bond strength of different resin based luting cements to lithium disilicate glass ceramic and to evaluate the type of fracture between lithium disilicate glass ceramic and the different resin based luting cement using Scanning electron microscope.

\section{Materials and Methods}

The study included a total of 30 inlay wax patterns which was fabricated and customized to get the desired size. Each inlay wax pattern had an external diameter of $10 \mathrm{~mm}$ and a thickness of $2 \mathrm{~mm}$. A total of 30 Lithium disilicate ceramic disks were fabricated using the lost wax and hot-pressed ceramic fabrication technology.

Each of these 30 Lithium disilicate ceramic disk were embedded in polymethylmethacrylate resin blocks in such a way that one surface of the disk remained uncovered to facilitate bonding procedures. All the specimen surfaces were treated with airborne particle abrasion to increase the surface area for bonding and to decrease the surface tension. To achieve proper surface texture and roughness all the specimens were assigned to surface conditioning by etching the ceramic substrates with $9 \%$ buffered hydrofluoric acid gel for 20 secs according to the manufacturer's regulations. The etched surfaces were washed and rinsed thoroughly to remove the residual acid after etching and air-dried and cleaned for 10 mins in an ultrasonic bath containing distilled water and then air-dried.

The ceramic specimens were divided into three groups that received different cements Group 1: RelyX Ultimate Clicker, Group 2: Fusion Self Lute and Group 3: ParaCore.

Following debonding, all fractured interfaces were visually analysed from the Scanning electron microscope photomicrographs to determine the mode of fracture.

The fracture modes were classified into one of the three types based upon the percentage of remaining resin on the bonding surface of the specimen.

1. Adhesive failure at the ceramic-luting cement interface (A)

2. Cohesive failure both inside the luting cement and ceramic $(\mathrm{C})$

3. Combination of adhesive and cohesive failures with occasional crack propagation inside the ceramic (AC)

\section{Results}

\section{Shear bond strength}

The study results revealed that shear bond strength values for ParaCore was significantly lower (3.732 $\mathrm{MPa})$. However, there was no statistical difference in the mean shear bond strength values between RelyX and Fusion Self Lute was found $(p=0.978)$. The results of the shear bond strength test for RelyX, Fusion Self Lute and ParaCore was 6.387 MPa, 6.204 MPa and 3.732 MPa, respectively.

Tukey test was used for comparing the bond strengths between the three groups. Comparison of bond strength of RelyX and Fusion Self Lute luting agents demonstrated that RelyX was substantially superior in bond strength ( $\mathrm{p}=0.978$ ), between RelyX and ParaCore showed that RelyX was substantially superior in bond strength $(\mathrm{p}=0.019)$ and between Fusion Self Lute and ParaCore revealed that Fusion Self Lute was superior in bond strength $(\mathrm{p}=0.030)$.

\section{Failure type Analysis}

Failure modes observed between the luting agent and the ceramic were influenced by the type of surface treatment and the luting agent used. The most frequent fracture modes were cohesive fracture with RelyX and Fusion Self Lute cement (Fig. 1 and 2). No cohesive fracture within the ceramic substrate was observed. The number of adhesive failures was predominantly higher for ParaCore cement (Fig. 3).

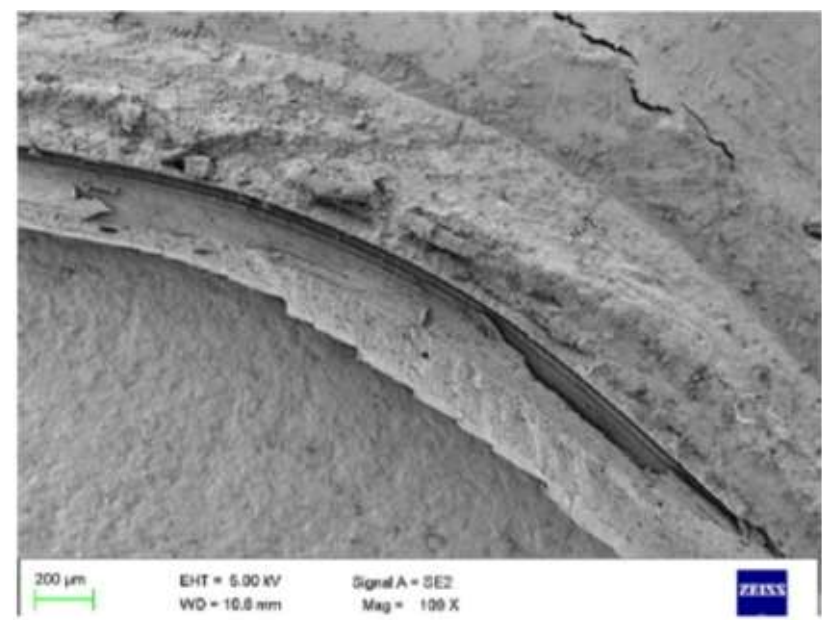

Fig. 1: SEM micrograph of a cohesive resin fracture with RelyX ${ }^{\mathrm{TM}}$ Ultimate Clicker $^{\mathrm{TM}}$ - 3M ESPE

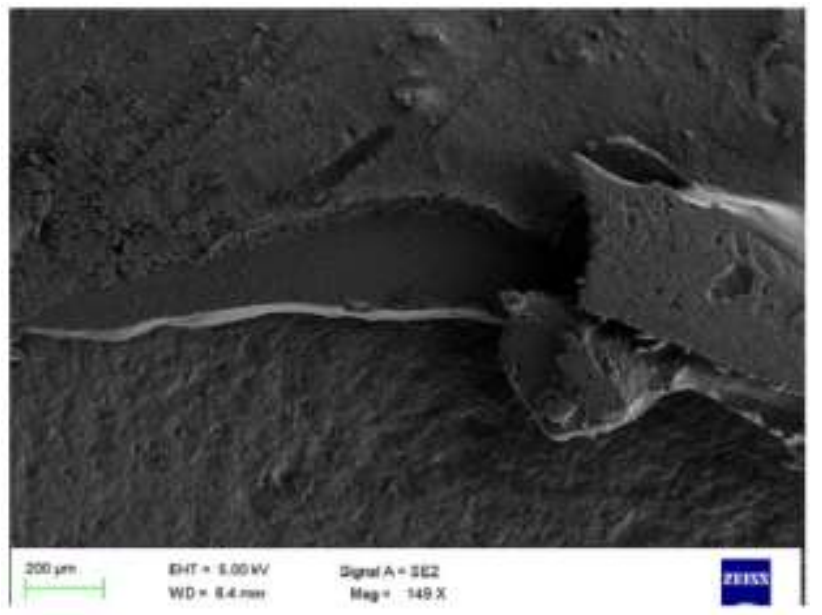

Fig. 2: SEM micrograph of a cohesive resin fracture with Fusion Self Lute ${ }^{\mathrm{TM}}-$ Prevest DenPro® 


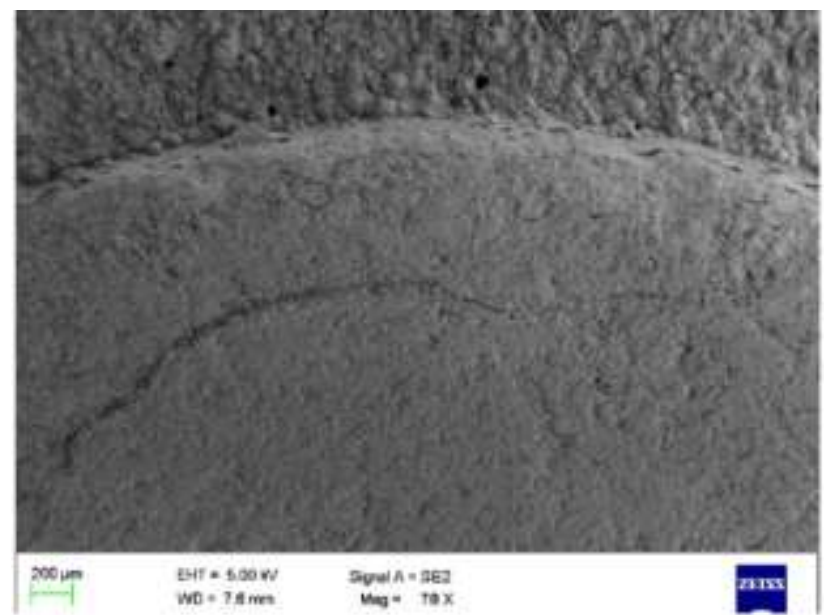

Fig. 3: SEM micrograph of a adhesive resin fracture with ParaCore ${ }^{\circledR}$-Coltene

The failure modes were classified as cohesive failure (fracture within the resin), adhesive failure (fracture at the interface between the ceramic and adhesive layer) and mixed failures (including interface/ceramic, interface/resin).

A post hoc test, Tukey test was employed to see if there was any statistically significant difference among the study groups. There was no statistical significant difference between Group 1 and Group 2 while there was statistically significant difference between Group 1 and Group 3 $(\mathrm{p}=0.019, \mathrm{p}<0.05)$ and Group 2 and Group $3(\mathrm{p}=0.03$, $\mathrm{p}<0.05)$ (Fig.4).

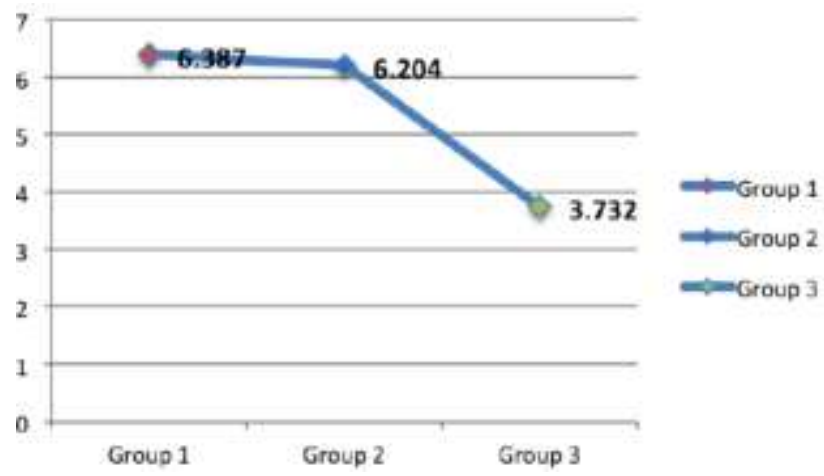

Fig. 4 Difference in mean bond strength among groups

\section{Discussion}

The inclusion of lithium dioxide crystals to glass ceramics resulted in great improvement in its mechanical properties and provided a material that has multiple clinical applications. $^{15}$

Lithium disilicate ceramics (LDCs) have two components: silica, which serves as the glassy matrix and lithium oxide (Li2O) crystals, which serve as a flux used to lower the processing temperature of the glassy matrix from approximately $2000^{\circ} \mathrm{C}$ to $1100^{\circ} \mathrm{C}$.

LDCs have an unusual microstructure, consisting of small interlocking, plate or needle like crystals that are randomly oriented, act as crack stoppers, and provide a substantial increase in flexural strength compared to conventional glass ceramics.

Resin bonding of all-ceramic restorations decreases the risk of fracture. Adequate adhesion between ceramic and tooth substance is required for the successful function of ceramic restorations. Type of luting cement is one of the vital factors that influences the bond strengths. ${ }^{16}$

The clinical success of many indirect ceramic restorations depends on the properties of a luting agent and the surface treatments for ceramic surfaces. ${ }^{17}$

The bond strength between resin and a ceramic surface depends on the micromechanical interlocking and chemical bonding, which require roughening and cleaning of the surface for adequate activation. ${ }^{18}$ Several pretreatment procedures have been used clinically to produce a better micromechanical retentive ceramic surface. ${ }^{19}$

Studies conducted by Chen JH, Matsumara and Sorensen JA have demonstrated that HF solutions between $2.5 \%$ and $10 \%$ applied for 2 to 3 minutes seem to be most efficacious. $^{18,20,21}$

Modern surface conditioning methods, a recent introduction, require airborne particle abrasion of the surface before bonding in order to achieve high bond strength. One such system is silica coating. Air-particle abrasion is a prerequisite for achieving sufficient bond strength between the resins and ceramics.

Thus, it is important to identify the most reliable and effective method of bonding both at the cement/tooth and the cement/ceramic restoration interface. In one such surface conditioning method, the surfaces are air abraded with aluminium trioxide particles modified with silica. ${ }^{22-25}$

Kupiec et al, conducted an in vitro study and reported that sole airborne particle abrasion provides insufficient bond strengths and excessive airborne particle abrasion induced chipping or a high loss of ceramic material. ${ }^{26} \mathrm{~A}$

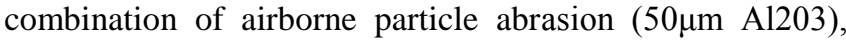
etching with $\mathrm{HF}$ acid, and application of a silane coupling agent is recommended. ${ }^{27-29}$

Several authors have shown high standard deviations after surface treating ceramic substrates when compared to not treating the ceramic surface, and this could be attributed to the fact that the poorly adherent precipitates that are deposited at the bottom surface of the grooves and channels, created by acid treatment and rinsing, may weaken resin ceramic bonds and lead to failure. ${ }^{30,31}$

The results of the present study revealed that several factors interact in the process of establishing a strong bond between two different materials. The first factor is the mechanical properties of the substrate material. The second factor is the surface roughness of the bonding substrate. SEM images of airborne-particle abraded specimens' demonstrated abrasion of both the glassy matrix and the reinforcing crystals, without creation of three-dimensional retentive features. Airborne particle abrasion is a routine step used to remove the reaction layer around pressed LDC. On the other hand, HF etching produced characteristic honeycomb irregularities and created a microporous surface by partially dissolving the glass phase, leaving behind an 
active surface rich in silica. ${ }^{32}$ The third factor is establishing a strong chemical bond between the substrate and the resin adhesive of choice, which is the function of the silane primer.

In this study the predominant mode of failure was cohesive mode of failure within the luting agent. Also, no cohesive failure within the ceramic was observed in any of the experimental groups. It is necessary for dentists to understand the characteristics of the ceramics and the surface conditioning methods in accordance with the cements to be chosen.

\section{Conclusion}

Resin based composites containing inorganic fillers embedded in an organic matrix are the material of choice for the adhesive luting of ceramic restorations. Amongst all the luting agents, ParaCore without filler particles showed the least value for shear bond strength. Higher value of shear bond strength was seen with RelyX Ultimate Clicker and Fusion Self Lute that consisted of silane filler particles and nano ceramic filler particles respectively. The predominant mode of failure was cohesive within the resin.

Though results of this study were obtained in vitro, results that increase the knowledge about shear bond strength are crucial for predicting the behaviour of resin based luting cements when bonded with silica based glass ceramic. This is especially true in the current scenario where the use of esthetic restorative materials like ceramics and the use of adhesive resin cements have increased tremendously.

It was concluded that resin cements containing filler particles show higher bond strength values when compared to resin cements with no filler particles. Also it can be concluded that bonds which fail by cohesion exhibit high strength performance.

\section{Conflict of Interest: None.}

\section{References}

1. Oh SC, Dong JK, L Cithy H, Scharer P. Strength and microstructure of IPS Empress 2 glass-ceramic after different treatments. Int J Prosthodont 2000;13(6):468-72.

2. Borges GA, Sophr AM, deGoes MF, Correr L, Chan DCN. Effect of etching and air borne particle abrasion on the microstructure of different dental ceramics. J Prosthet Dent 2003: 89:479-88.

3. Saracoglu ACC, Cotert HS. Effect of various surface treatment methods on the bond strength of the heat-pressed ceramic samples. J Oral Rehabil 31:790-97.

4. Bailey LF, Bennet RJ. DICOR surface treatments for enhanced bonding. J Dent Res 1988: 67:925-31.

5. Wolf DM, Powers JM, O'Keefe KL. Bond strength of composite to porcelain treated with new porcelain repair agents. Dent Mater 1992: 8:158-61.

6. Culp L. Empress 2. First year clinical results. J Dent Technol 1999;16:12-15.

7. Albakry M, Guazzato M, Swain MV. Effect of sandblasting, grinding, polishing and glazing on the flexural strength of two pressable all-ceramic dental materials. J Dent 2004;32:91-99.

8. Guazzato M, Albakry M, Ringer SP, Swain MV. Strength, fracture toughness and microstructure of a selection of all- ceramic materials. Part I. Pressable and alumina glassinfiltrated ceramics. Dent Mater 2004;20:441-48.

9. Rizkalla AS, Jones DW. Mechanical properties of commercial high strength ceramic core materials. Dent Mater 2004;20:207-12.

10. Della Bona A, Anusavice KJ, Shen C. Microtensile strength of composite bonded to hot-pressed ceramics. J Adhes Dent 2000;2:305-13.

11. Della Bona A, Anusavice KJ, Mecholsky JJ Jr. Failure analysis of resin composite bonded to ceramic. Dent Mater2003;19:693-699.

12. Gungor MA, Kucuk M, Dundar M, Karaoglu C, Artunc C. Effect of temperature and stress distribution on all-ceramic restorations by using a three-dimensional finite element analysis. J Oral Rehabil 2004;31:172-78.

13. Yeo IS, Yang JH, Lee JB. In vitro marginal fit of three allceramic crown systems. J Prosthet Dent. 2003;90:459-464.

14. Rosentritt M, Behr M, Handel G. Fixed partial dentures: allceramics, fibre reinforced composites and experimental systems. J Oral Rehabil 2003;30:873-877.

15. Gehrt M, Wolfart S, Rafai N, Reich S, Edelhoff D. Clinical results of lithium disilicate crowns after up to 9 years of service. Clin Oral Investig 17:275-84.

16. Kelly JR, Campbell SD, Bowen HK. Fracture-surface analysis of dental ceramics. J Prosthet Dent 1989;62:536-41.

17. Da Silva Ferreira S, Hanashiro FS, de Souza-Zaroni WC, Turbino ML, Youssef MN. Influence of aluminum oxide sandblasting associated with Nd:YAG or Er:YAG lasers on shear bond strength of a feldspathic ceramic to resin cements. Photomed Laser Surg 2010: 28(4):471-75.

18. Sorensen JA, Engelman MJ, Torres TJ, Avera SP. Shear bond strength of composite resin to porcelain. Inter J Prosthodont 1991: 4:17-23.

19. Osorio E, Toledano M, Silveira BL, Osorio R. Effect of different surface treatments on In-Ceram Alumina roughness. An AFM study. J Dent 2009:38:118-22.

20. Chen JH, Matsumura H, Atsuta M. Effect of etchant, etching period, and silane priming on bond strength to porcelain of composite resin. Oper Dent 1998;23:250-7.

21. Chen JH, Matsumura H, Atsuta M. Effect of different etching periods on the bond strength of a composite resin to a machinable porcelain. J Dent 1998;26:53-8.

22. Peutzfeldt A, Asmussen E. Silicoating. Evaluation of a new method of bonding composite resin to metal. Scand J Dent Res 1988;96:171 - 6.

23. Ozcan M, Pfeiffer P, Nergiz I. A brief history and current status of metal/ceramic surface conditioning concepts for resin bonding in dentistry. Quintessence Int 1998;29:713 - 24.

24. Ozcan M. The use of chairside silica coating for different dental applications: a clinical report. J Prosthet Dent 2002;87:469-72.

25. Ozcan M, Niedermeier W. Clinical study on the reasons for and location of failures of metal-ceramic restorations and survival of repairs. Int J Prosthodont 2002;15:299-302.

26. Kupiec KA, Wuertz KM, Barkmeier WW, Wilwerding TM Evaluation of porcelain surface treatments and agents for composite-to-porcelain re- pair. J Prosthet Dent 1996;76:11924.

27. Thurmond JW, Barkmeier WW, Wilwerding TM. Effect of porcelain surface treatments on bond strengths of composite resin bonded to porcelain. J Prosthet Dent 1994;72:355-9.

28. Shahverdi S, Canay S, Sahin E, Bilge A. Effects of different surface treatment methods on the bond strength of composite resin to porcelain. J Oral Rehabil 1998;25:699-705.

29. Pameijer CH, Louw NP, Fischer D. Repairing fractured porcelain: how surface preparation affects shear force resistance. J Am Dent Assoc 1996;127:203-9. 
30. Phoenix RD, Shen C. Characterization of treated porcelain surfaces via dynamic contact angle analysis. Int J Prosthodont 1995;8:187 - 94.

31. Canay S, Hersek N, Ertan A. Effect of different acid treatments on a porcelain surface. J Oral Rehabil 2001;28:95-101.

32. Roulet JF, Soderholm KJ, Longmate J. Effects of treatment and storage conditions on ceramic/composite bond strength. J Dent Res. 1995;74:381-87.

How to cite this article: Premnath $\mathrm{K}$, Prakash $\mathrm{N}$, Mohammed AB, Raheel SA. An in-vitro analysis of shear bond strength of resin based luting cements to lithium disilicate glass ceramic. Ann Prosthodont Restor Dent 2019;5(2):23-7. 